\title{
Construction of Large Volume Concrete for the Raft Foundation of the Basement
}

\author{
Yonggang Wang ${ }^{1}$ \\ Xijing University, Xi' an, 710123, China \\ e-mail: 791844501@qq.com
}

\author{
Shuai Wang ${ }^{2}$ \\ Xijing University, Xi'an, 710123, China \\ e-mail:975256365@qq.com
}

\begin{abstract}
This paper analyzes the construction technology of large volume concrete for the raft foundation of the basement with engineering examples. In view of the difficulties in the construction of raft foundation, the design of concrete mix proportion, the temperature of the concrete into the mold, the concrete pouring and maintenance of concrete are discussed, which provides a theoretical basis for the construction of mass concrete.
\end{abstract}

Keywords-Raft foundation; Mass concrete; Construction technology; Concrete crack

\section{ENGINEERING SURVEY}

This paper takes a building in the basement raft foundation engineering as an example, analysis and research the construction of large volume concrete of raft foundation for, the project for 20 layer on the upper part and underground part for layer 2, the project area foundation is strong weathering gravel argillaceous sandstone, artificial foundation takes raft foundation. The length of the raft foundation is $60 \mathrm{~m}$, width of $20 \mathrm{~m}$, in the center of the bottom plate part, set a post pouring belt based along the short side direction, the average thickness of the floor is about $2 \mathrm{~m}$, bottom reinforcement using $\Phi 22$ ( 100 bar, use impermeability concrete, namely, S8, C40, total amount of more than 5000 cubic meters, belonging to the large volume concrete project.

\section{CONSTRUCTION DIFFICULTIES OF LARGE VOLUME CONCRETE CONSTRUCTION OF RAFT FOUNDATION}

Due to its own characteristics, there are some difficulties in the construction process of the raft foundation of large volume concrete, mainly including the following aspects:

(1) due to its big volume and concrete volume, in the construction process must be strictly control the pouring quality of concrete, reduce the concrete temperature cracks and shrinkage cracks, to ensure that the basic structure of the cracks to meet the requirements of specifications, in accordance with the specification of structural waterproof and strength requirements. ${ }^{[1]}$

(2) Due to the foundation soil will produce a certain disturbance in the construction process, so in the process of foundation concrete engineering, the adverse impact on foundation soil in the construction must be fulled considered, and necessary measures must be taken to reduce the disturbance, to ensure that the foundation soil strength, bearing capacity and the overall stability meet the design requirements.

(3) This project uses S8, C40 concrete. Due to the large amount of concrete pouring, a large amount of hydration heat is produced, which makes the temperature rise sharply, especially in the hot summer, it must be strictly controlled the temperature of the mold, to ensure the quality of concrete works.

\section{CONCRETE DESIGN}

Concrete mix ratio design is the most important foundation work in the basement raft foundation engineering, mix proportion determines the concrete overall strength, slump, dosage of cement, hydration heat, initial setting and end setting time a number of technical indicators. ${ }^{[2]}$ This project uses S8, C40 anti permeability of concrete, the design strength of concrete is C40 and tentatively concrete slump should be controlled at about $140 \mathrm{~mm}$. At the beginning of the coagulation time to develop for about 10 hours, by adding an appropriate amount of flying ash and reducing agent and other materials to reduce the amount of cement, to reduce the heat of hydration of concrete generated in the initial setting process. $^{[3]}$

According to the market survey and indoor test research, decided to use grade II pulverized coal ash as one of the admixture, by adding flying ash to fill the internal porosity of concrete, improving the compactness of concrete, thereby reducing water cement ratio and reduce the heat of hydration of concrete generated in the project, improving the impermeability, reducing the temperature shrinkage cracks of concrete. In this project, the choice of concrete strength is relatively high, the required amount of cement is large, the generated hydration heat in the process is relatively high, through the indoor tests determine the grade II of finely ground fly ash admixture for $81 \mathrm{~kg} / \mathrm{m}^{3}$. For the large volume concrete project, it is not enough to reduce the hydration heat. ${ }^{[4]}$ Therefore, it is proposed that the KFDN-SP type high efficiency water reducing agent is used to reduce the water consumption of concrete, so as to improve the construction of concrete workability and pumpability, reduce the concrete in the possibility of curing process of late drying shrinkage cracks. Through laboratory tests, the amount of water reducing retarder is determined by 8.4 $\mathrm{kg} / \mathrm{m}^{3}$. ${ }^{[5]}$ Through indoor test and mixing station for verification, the concrete mix proportion design will be determined after repeating test match, as shown in Table 1 below.

Through the test, mixed concrete initial setting time is 14.1 hours; the slump is $157 \mathrm{~mm}$, which conforms to the specification and design requirements. 


\section{CONTROLLING CONCRETE TEMPERATURE}

High strength concrete and mass concrete into the mold temperature has important influence on the construction quality. Reducing and controlling the temperature of concrete and reducing the temperature change can effectively reduce the temperature shrinkage crack of mass concrete. In the construction process it's better to use low temperature cold water for concrete mixing, and in front of the mixing can consider spraying cold water to reduce the temperature of the aggregate, and storage of materials and transport process should make cooling works. Considering the engineering concrete mixing and pouring construction in the period of low temperature, outside temperature generally is about $20{ }^{\circ} \mathrm{C}$, for raw materials for cooling treatment, by the method of TLC rapid pouring, increase the heat radiating area of the concrete, reduce internal and external temperature of large volume concrete. Through various measures, reduce the temperature of concrete, the temperature of the concrete is below $25^{\circ} \mathrm{C} .{ }^{[6]}$ Embedded within the concrete temperature sensor at the same time, on the concrete internal temperature of real-time process control, three temperature monitoring points are arranged in the concrete in the center and edge, each monitoring point buried three temperature sensors, measured and recorded temperature every $1 \mathrm{~h}$.

\section{CONCRETE POURING}

For the large volume concrete of raft foundation of the basement, good concrete pouring work must be made according to the concrete construction technology requirements and basic engineering design requirements, on the raft foundation of large volume concrete pouring way for reasonable planning, concrete pouring with location divided into two parts, the two parts of the construction, each part is equipped with a concrete pumping machine, using the Ladder cant layered casting method. The thickness of each layer is controlled at about $40 \mathrm{~cm}$, and the layered casting is carried out according to the schematic diagram shown in Figure 1. The whole casting process must have the supervision personnel and the relevant technical personnel in the field, the interval time of each pouring layer cannot be lower than the initial setting time of concrete, the concrete reaches certain strength and then carries on the next layer.

After the completion of concrete pouring, then the vibration of concrete can be carried out in accordance with the slope of the natural formation of the natural formation of fixed vibration. ${ }^{[7]}$ A general set of four vibrating point, in concrete pumping pipe outlet, at the center position of slope are respectively provided with a vibration tamping points, at the foot of the slope setting two vibration tamping point. Large volume concrete must strictly control the vibration tamping quality, to prevent the leakage of shock, to avoid excessive vibration, to prevent segregation even leakage.

In large volume concrete construction of raft foundation, floor than structural surface position is easy to produce cracks in the surface, which is mainly in initial setting and final setting process will lose a lot of water and settlement joint caused by concrete. After the pouring and vibrating of concrete, it's to use of scraping ruler on the existence of defects on the surface of the concrete for leveling, and then use the vibration plate vibrator again vibrating, ensure concrete reaches the compactness requirement specification, after the initial setting of concrete end before setting on the concrete surface by wiping pressure treatment, eliminate the shrinkage crack of concrete surface.

\section{FLOOR DRAINING WATER PROCESSING}

The engineering foundation soil is the strong weathered gravel sand, and the bottom plate is in contact with the foundation soil, and there is the possibility of water seepage in the confined fissure, which requires a good foundation soil water drainage work. Combined with the characteristics of the project, the use of blind ditch and water collection wells to reduce the drainage, the treatment should reach the surface below the bottom surface of the cushion at least $30 \mathrm{~cm}$. The collection wells are generally set in the excavation of the deep well, the column pier and other position, with the retaining wall at least $2 \mathrm{~m}$. ${ }^{[8]}$ The excavation of the Wells and blind ditch should be set after the completion of the construction of the foundation floor cushion and before concrete engineering construction, and added cushion layer and the waterproof layer.

\section{CONCRETE CURING}

Large volume concrete engineering maintenance to do concrete temperature control, concrete in the hydration process will release a lot of heat of hydration, in large volume concrete in this part of the heat of hydration is difficult to rapid loss, and therefore makes the concrete internal temperature rises rapidly, inside and outside will produce large temperature difference to induce shrinkage cracks. This project uses laying circulation pipe method inside the floor to reduce concrete internal temperature. Circulating water pipes use the steel pipe,with the diameter of $20 \mathrm{~mm}$ setting in the side of the bottom center position and are arranged evenly along the horizontal direction with the tube spacing of $80 \mathrm{~cm}$, laying as far as possible, which has direct contact with reinforcement, promotes the cooling by heat conduction performance of the steel bar. In addition to do a good job in the internal cooling of large volume concrete, it is also necessary to do a good job in the internal temperature detection, the concrete internal temperature monitoring ensure that the temperature difference between inside and outside of the concrete does not exceed the standard requirements. Temperature monitoring device mainly comprises a Temperature probe and the temperature meter, temperature probe the general embedded in the interior of the concrete, through a data line the data transmission to temperature instrument, temperature instrument and the temperature of comprehensive analysis. Temperature monitoring points are generally set in the concrete surface, center, and the lower surface; each monitoring point can be set up 3 temperature probe. ${ }^{[9]}$ In the beginning of concrete hydration, the temperature monitoring and a data collection must be carried out every three hours, the temperature difference between the inside and outside of the concrete shall not exceed $25^{\circ} \mathrm{C}$.

During the concrete curing, the demolition of the template should be taken in the concrete temperature the same as the air temperature, in order to avoid cracking in the template. ${ }^{[10]}$ When there are no obvious footprints on the surface on the concrete, it means that the concrete 
reaches the certain intensity, then heat preservation and moisture can be carried out. can be covered in the concrete surface of plastic film or sacks, and according to the outside weather temperature increase or decrease the cover of the. When setting the tank insulation, moisture curing, should according to the detected internal temperature control circulating water temperature, control of concrete temperature difference between inside and outside.

\section{CONCLUDING REMARKS}

The characteristic of the raft foundation engineering of the basement is the mass concrete construction. The main points of quality control are to avoid the temperature shrinkage crack and dry shrinkage crack. In the process of construction, reasonable measures should be taken from the concrete mix proportion design, control concrete pouring, maintenance work, which must be in strict accordance with the construction process and specification requirements for construction, to ensure the engineering quality.

\section{Figures and Tables}

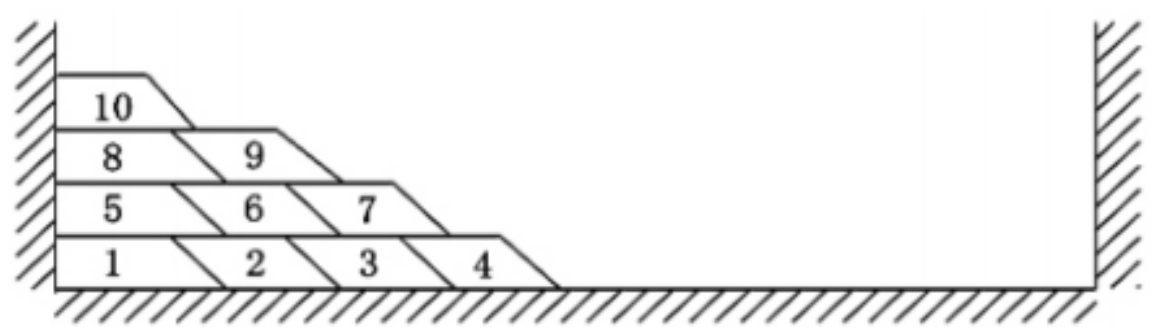

Figure 1.

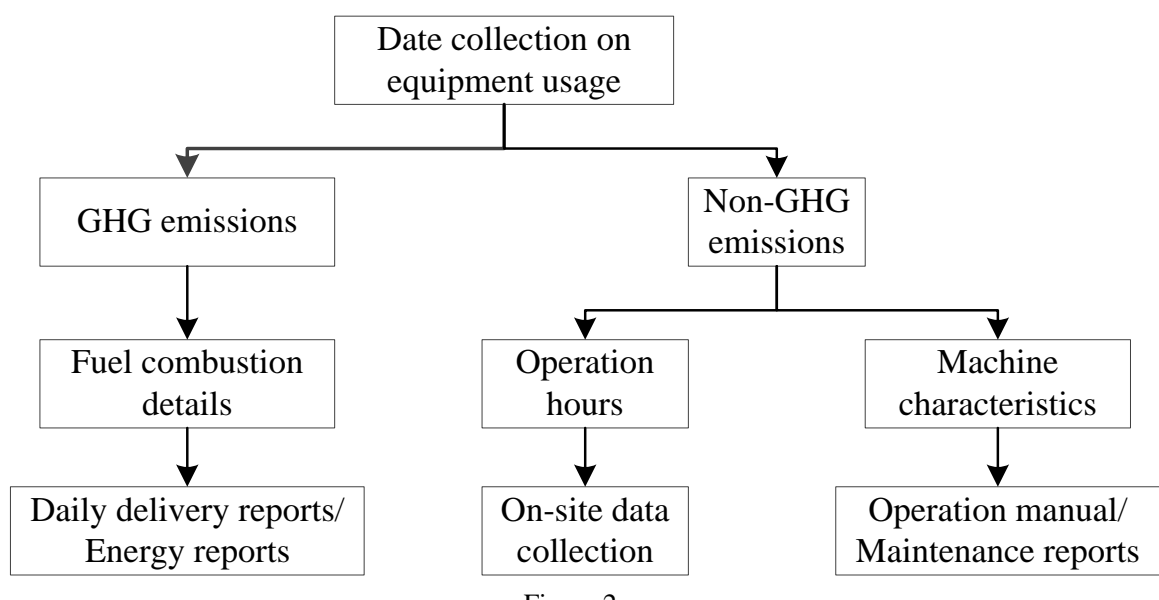

Figure 2.

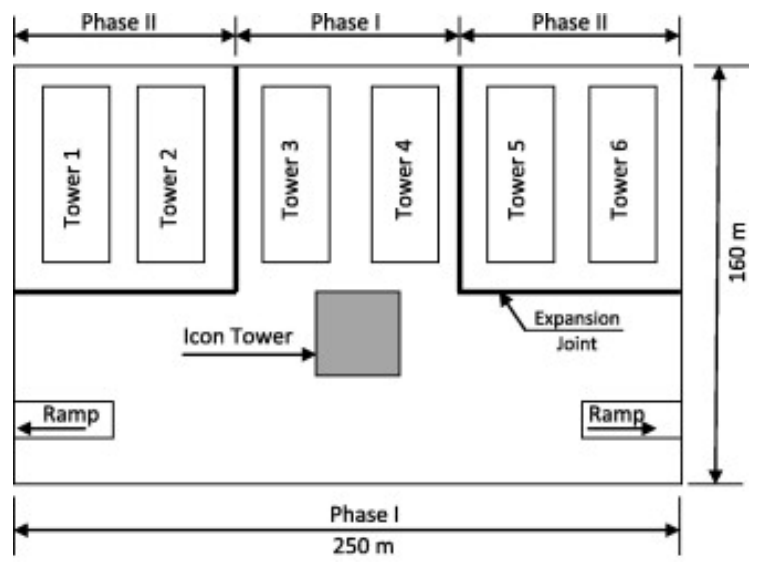

Figure 3. 


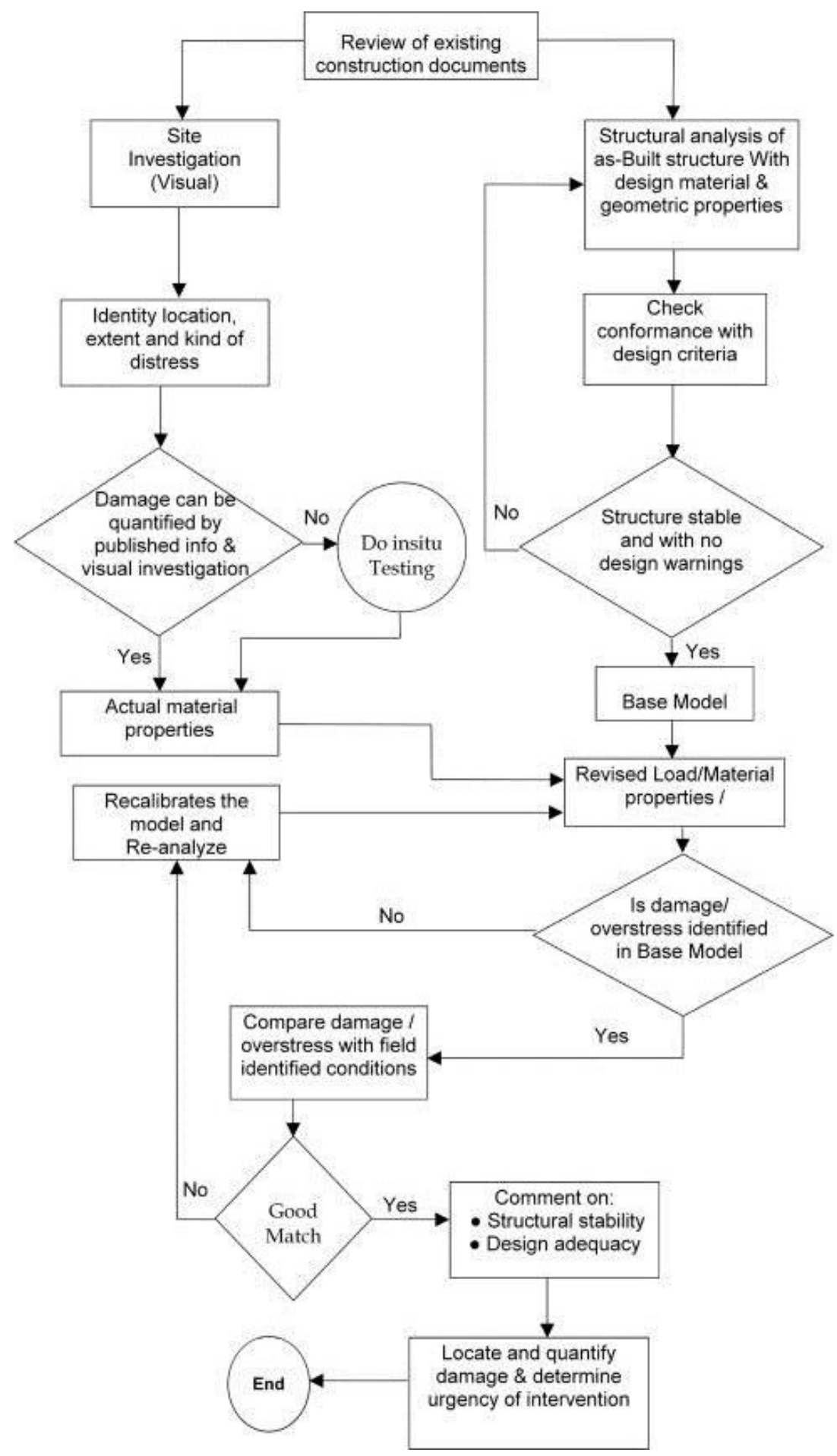

Figure 4.

\section{REFERENCES}

[1] BS 8102, Code of practice for protection of below grade structures against water from the ground. British Standards Institution; 2009.

[2] Chew MYL, Nayanthara DS. Factors affecting water-tightness in wet area of high-rise residential buildings. Archit Sci Rev 2002;45(4):375-83

[3] CIB, Building pathology: a state-of-the-art report. CIB Report Publication 155. CIB Working Commission W86. International Council for Building Research and Information, Holland; 1993.

[4] P. Kitiyodom, T. Matsumoto, K. Kawaguchi.A simplified method for piled raft foundations subjected to ground movements induced by tunnelling.Int J Num Anal Meth Geomech, 29 (2005), pp. 1485-1507

[5] O. Reul, M.F. Randolph.Piled rafts in overconsolidated clay: comparison of in-situ measurements and numerical analyses.Géotechnique, 53 (3) (2003), pp. 301-315

[6] O.C. Zienkiewicz, R.L. Taylor, J.Z. Zhu.The finite element method - its basis and fundamentals(6th ed.)Elsevier, London (2005)

[7] Varun, D. Assimaki, A. Shafieezadeh.Soil-pile-structure interaction simulations in liquefiable soils via dynamic macroelements: formulation and validation.Soil Dyn Earthq Eng 47 (2013), pp. 92-107

[8] H. Asega, T. Arai, K. Akira, J. Suzumura, K. Hanada, H Shiojuri, et al.A dynamic response analytical method of soil pile 
system using dynamic interaction spring.J Struct Construct Eng (526) (1999), pp. 45-52

[9] A.M. Kaynia, E. Kausel.Dynamics of piles and pile groups in layered soil media.Soil Dyn Earthq Eng, 10 (8) (1991), pp. 386401
[10] G. Gazetas, K. Fan, A.M. Kaynia, E. Kausel.Dynamic interaction factors for floating pile groups.J Geotech Eng ASCE, 117 (10) (1991), pp. 1531-1548 